\title{
Genomic and biologic comparisons of cyprinid herpesvirus 3 strains
}

\author{
Yuan Gao ${ }^{1}$, Nicolás M. Suárez², Gavin S. Wilkie², Chuanfu Dong ${ }^{3}$, Sven Bergmann ${ }^{4}$ Pei-Yu Alison Lee ${ }^{5}$, \\ Andrew J. Davison ${ }^{2}$, Alain F. C. Vanderplasschen ${ }^{1 *}$ (D) and Maxime Boutier ${ }^{1}$
}

\begin{abstract}
Cyprinid herpesvirus 3 (CyHV-3) is the archetypal fish alloherpesvirus and the etiologic agent of a lethal disease in common and koi carp. To date, the genome sequences of only four CyHV-3 isolates have been published, but no comparisons of the biologic properties of these strains have been reported. We have sequenced the genomes of a further seven strains from various geographical sources, and have compared their growth in vitro and virulence in vivo. The major findings were: (i) the existence of the two genetic lineages previously described as European and Asian was confirmed, but inconsistencies between the geographic origin and genotype of some strains were revealed; (ii) potential inter-lineage recombination was detected in one strain, which also suggested the existence of a third, as yet unidentified lineage; (iii) analysis of genetic disruptions led to the identification of non-essential genes and their potential role in virulence; (iv) comparison of the in vitro and in vivo properties of strains belonging to the two lineages revealed that inter-lineage polymorphisms do not contribute to the differences in viral fitness observed; and ( $v$ ) a negative correlation was observed among strains between viral growth in vitro and virulence in vivo. This study illustrates the importance of coupling genomic and biologic comparisons of viral strains in order to enhance understanding of viral evolution and pathogenesis.
\end{abstract}

\section{Introduction}

Cyprinid herpesvirus 3 (CyHV-3; genus Cyprinivirus, family Alloherpesviridae, order Herpesvirales), also known as koi herpesvirus (KHV), is the etiologic agent of a lethal disease in common and koi carp (Cyprinus carpio) [1]. Since its emergence in the late 1990s, this highly contagious and dreadful disease has spread worldwide [2] and caused severe economic losses [3, 4]. CyHV-3 has been the subject of a growing number of studies and is considered to be the archetypal fish alloherpesvirus [1].

The CyHV-3 genome is $295 \mathrm{kbp}$ in size and thus the largest described among all herpesviruses [5]. The complete DNA sequences of four CyHV-3 isolates derived from various geographical locations have been determined [6, 7]. Analyses of these sequences revealed a high

\footnotetext{
*Correspondence: a.vdplasschen@uliege.be

${ }^{1}$ Immunology-Vaccinology, Department of Infectious and Parasitic Diseases (B43b), Fundamental and Applied Research for Animals \& Health (FARAH), Faculty of Veterinary Medicine, University of Liège, Liège, Belgium

Full list of author information is available at the end of the article
}

level of genomic identity (>99\%), with inter-strain diversity comprising mainly single nucleotide polymorphisms (SNPs) and minor insertions or deletions (indels). They also indicated the existence of two main genotypic lineages initially termed European (based on one strain isolated in Israel and one strain originating from the USA) and Asian (based one strain isolated in Japan). Low interstrain diversity and an association of these two lineages with geographic origin were further confirmed by PCRbased partial sequencing of a few variable markers for a substantial number of viral samples $[8,9]$. However, preliminary data suggested that the situation might be more complex, as some strains originating from Europe resembled the Asian lineage, and vice versa $[6,8,10]$. Moreover, the coexistence in a single genome of loci belonging to both lineages suggested that recombination may have occurred [11]. However, definitive conclusions regarding these issues are difficult to make, since partial sequencing covering only a few loci was performed.

Many of the sequence differences between CyHV-3 strains concern indels caused by variable number of

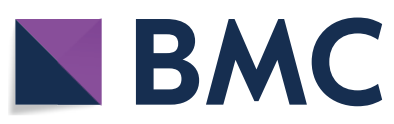

(c) The Author(s) 2018. This article is distributed under the terms of the Creative Commons Attribution 4.0 International License (http://creativecommons.org/licenses/by/4.0/), which permits unrestricted use, distribution, and reproduction in any medium, provided you give appropriate credit to the original author(s) and the source, provide a link to the Creative Commons license, and indicate if changes were made. The Creative Commons Public Domain Dedication waiver (http://creativecommons.org/ publicdomain/zero/1.0/) applies to the data made available in this article, unless otherwise stated. 
tandem repeats (VNTRs). VNTR polymorphism has shown some utility for differentiating strains of large DNA viruses, such as human herpesvirus 1 [12]. Analysis of multiple VNTR loci in CyHV-3 provided further support for the existence of the two main lineages described above, and, in addition, 87 haplotypes were identified [13, 14]. The discriminatory power of VNTRs is nonetheless more suited to fine tuning the tips of phylogenetic trees based on non-VNTR polymorphisms (SNPs and indels) [1]. Unfortunately, robust phylogenetic classification of this sort is lacking for CyHV-3 strains due to the low number of complete genome sequences available. This deficiency could be overcome using genome-wide analysis of multiple viral strains by high-throughput sequencing. This approach has been used successfully for several other herpesviruses, including human herpesvirus 1 [15], to give a much fuller picture of strain diversity [16]. Indeed, it was recently applied to sequencing CyHV-3 directly from infected fish tissues, without first isolating viral strains [17]. However, multiple strains were detected in each tissue, potentially causing the derived genome sequences to be artificial composites of the individual strains present.

In our study, we sequenced seven strains of CyHV-3 from various geographical origins, and compared their growth in vitro and virulence in vivo. We confirmed the existence of the two genetic lineages described previously as European and Asian, but identified inconsistencies between the geographic origin and the lineage of few strains. Potential inter-lineage recombinations were also demonstrated, which suggested the existence of a third, as yet unidentified lineage. Analyses of CyHV-3 genes that are disrupted, and therefore non-functional, led to the identification of several non-essential genes, some of which may affect virulence. Finally, a negative correlation was established between viral growth in vitro and virulence in vivo. Overall, our study illustrated the potential of comparing the genomic and biologic characteristics of viral strains in studying viral evolution and pathogenesis.

\section{Materials and methods \\ Cells and viruses}

Common carp brain (CCB) cells [18] were cultured in minimum essential medium (Sigma) containing $4.5 \mathrm{~g} / \mathrm{L}$ glucose (D-glucose monohydrate; Merck) and 10\% (v/v) fetal calf serum (FCS). The cells were cultured at $25^{\circ} \mathrm{C}$ in a humid atmosphere containing 5\% $\mathrm{CO}_{2}$. A total of seven $\mathrm{CyHV}-3$ strains from various geographic origins were used (Table 1). The Cavoy strain was amplified from a commercial aliquot of an attenuated vaccine produced by passage in cell culture of an isolate from Israel [1921]. The $T$ strain was subcloned from a large viral plaque obtained after 30 passages of a Taiwanese isolate on a
Table 1 CyHV-3 strains

\begin{tabular}{llll}
\hline Name $^{\text {a }}$ & Geographic origin & $\begin{array}{l}\text { GenBank accession } \\
\text { number }\end{array}$ & References \\
\hline FL & Belgium & MG925487 & {$[45]$} \\
M3 & Belgium & MG925490 & {$[46]$} \\
I & Israel & MG925489 & {$[46]$} \\
Cavoy & Israel & MG925485 & {$[19-21]$} \\
E & United Kingdom & MG925486 & {$[47]$} \\
T & Taiwan & MG925491 & {$[47]$} \\
GZ11-SC & China & MG925488 & {$[6]$} \\
U & USA & DQ657948.1 & {$[7]$} \\
KHV-I & Israel & DQ177346.1 & {$[7]$} \\
$J$ & Japan & AP008984.1 & {$[7]$} \\
GZ11 & China & KJ627438.1 & {$[6]$} \\
\hline
\end{tabular}

a The first seven viral strains listed were used in this study.

koi fin cell line [22]. GZ11-SC is a subclone of the GZ11 strain from China [6]. It was generated by transfection of GZ11 DNA into CCB cells, followed by plaque purification of the regenerated virus.

\section{Genetic characterization of CyHV-3 strains}

Viral DNA from CyHV-3 strains was characterized by restriction fragment length polymorphism using SacI digestion, and further characterized by full-length genome sequencing using methods described previously $[23,24]$. Sequences have been deposited to the GenBank.

\section{Phylogenetic analysis}

A multiple alignment of 11 full-length viral genome sequences was made using MAFFT online version 7 [25]. The sequences included the seven produced in this study and the four available in GenBank for the U, J, KHV-I and GZ11 isolates (Table 1) [6, 7]. The phylogenetic tree was generated using the UPGMA method (unweighted pairgroup method with arithmetic means) implemented in the MEGA6 software [26], and evaluated by the interior branch test method with 1000 bootstraps.

\section{Recombination analysis}

Detection of inter-strain recombination, identification of closest parental sequences and localization of possible recombination break points were carried out using the Recombination Detection Program 4 (RDP4) [27]. This software combines a variety of independent methods, including RDP [28], GENECONV [29], BOOTSCAN [30], MaxChi [31], CHIMAERA [32], SISCAN [33] and 3SEQ [34]. 


\section{Viral growth curve assay}

Triplicate cultures of CCB cells were infected with each CyHV-3 strain at a multiplicity of infection (MOI) of 0.05 plaque-forming unit (pfu)/cell. After an incubation period of $2 \mathrm{~h}$, the cells were washed with phosphate-buffered saline and overlaid with Dulbecco's modified essential medium (DMEM, Sigma) containing $4.5 \mathrm{~g} / \mathrm{L}$ glucose and $10 \%(\mathrm{v} / \mathrm{v})$ FCS. The supernatant was removed from infected cultures at successive intervals $(0,2,4,6$ and 8 days post-infection (dpi)), and stored at $-80{ }^{\circ} \mathrm{C}$. Viral titration was carried out by duplicate plaque assays in CCB cells using methods described previously [35].

\section{Viral plaque size assay}

CCB cells were cultured in six-well plates and inoculated with $200 \mathrm{pfu} /$ well of CyHV-3 for $2 \mathrm{~h}$ and overlaid with DMEM containing $4.5 \mathrm{~g} / \mathrm{L}$ glucose, $10 \%(\mathrm{v} / \mathrm{v})$ FCS and $1.2 \%(\mathrm{w} / \mathrm{v})$ carboxymethylcellulose (medium viscosity, Sigma). Viral plaques were treated for indirect immunofluorescent staining by using monoclonal antibody $8 \mathrm{G} 12$, which recognizes an unidentified CyHV-3 nuclear protein. Plaques were imaged by using a Nikon A1R confocal microscope, and plaque size was measured by using the ImageJ software [36].

\section{Fish}

Common carp were kept in $60 \mathrm{~L}$ tanks at $24{ }^{\circ} \mathrm{C}$. Water parameters were checked twice per week. Microbiological, parasitic and clinical examinations carried out immediately prior to the experiments demonstrated that the fish were healthy. All experiments were preceded by an acclimation period of at least 2 weeks.

\section{Inoculation of fish}

Fish were infected by immersion in constantly aerated water containing $400 \mathrm{pfu} / \mathrm{mL}$ of virus for $2 \mathrm{~h}$ at room temperature, the volume of water being adjusted to a biomass of approximately $10 \%$ according to fish size and number. At the end of the incubation period, the fish were returned to the initial tank.

\section{Ethics statement}

The experiments, maintenance and care of fish complied with the guidelines of the European Convention for the Protection of Vertebrate Animals used for Experimental and other Scientific Purposes (CETS No. 123). The animal studies were approved by the local ethics committee of the University of Liège, Belgium (laboratory accreditation No. 1610008, protocol No. 1059). All efforts were made to minimize animal suffering.

\section{Statistical analysis}

Viral plaque sizes and viral growth curves were compared by two-way ANOVA (analysis of variance) with interactions followed by Bonferroni post hoc test. Survival curves were compared by using Log-rank tests. Correlation analyses were done by Pearson two-tailed $r$ test, and illustrated by linear regression, using Graphpad Prism 5. Statistical analyses of recombination events were generated with the RDP4 software. Calculation of $p$ values is based on binomial distribution (RDP), Blast-Like KarlinAltschul \& Permutation (GENECONV), Bootstrapping \& binomial distribution \& Chi squared test (BOOTSCAN), Chi squared test \& permutation (MaxChi, CHIMAERA), Permutation \& Z Test (SISCAN) and Exact test (3SEQ). Statistical significance was represented as follows: $n s$ not significant; * $p<0.05$; ** $p<0.01$; and ${ }^{* * * *} p<0.001$.

\section{Results}

The goal of our study was to gain insights into the evolution and pathogenesis of $\mathrm{CyHV}-3$ by performing coupled genomic and biologic comparisons. With this goal in mind, seven viral strains were selected (Table 1). These strains originated from various countries and were supposed to represent the European and the Asian lineages of CyHV-3.

\section{Full-length genome analyses}

Phylogenetic analysis of the seven new genome sequences and the four published sequences (Table 1) confirmed the high level of similarity (>99\% identity) reported previously. The existence of two major phylogenetic lineages was also confirmed (Figure 1), and a correlation was observed between geographic origin and viral lineage for most strains. However, strain M3 branched in the Asian lineage despite having been isolated in Europe, and strain GZ11 (and its subclone GZ11-SC) had a monophyletic origin with the European lineage despite having been isolated in China. The intermediate position of the GZ11 strain hinted that it may have been generated by recombination between the two lineages. This hypothesis was supported by examination of a genome sequence alignment (data not shown).

\section{Recombination}

To explore potential inter-strain recombination, the eleven full-length genomes were analyzed using the RDP4 software. Potential recombination events were detected only in strain GZ11 and its subclone (Table 2 and Figure 2). The results suggested that strain GZ11 consists of a genome in the European lineage (Figures 2B, $\mathrm{E}$ and $\mathrm{H}$ ) in which three recombination events have occurred. One (Figures $2 \mathrm{~A}-\mathrm{C}$ ) represented the acquisition of $5.5 \mathrm{~kb}$ from the left end of the genome from a 


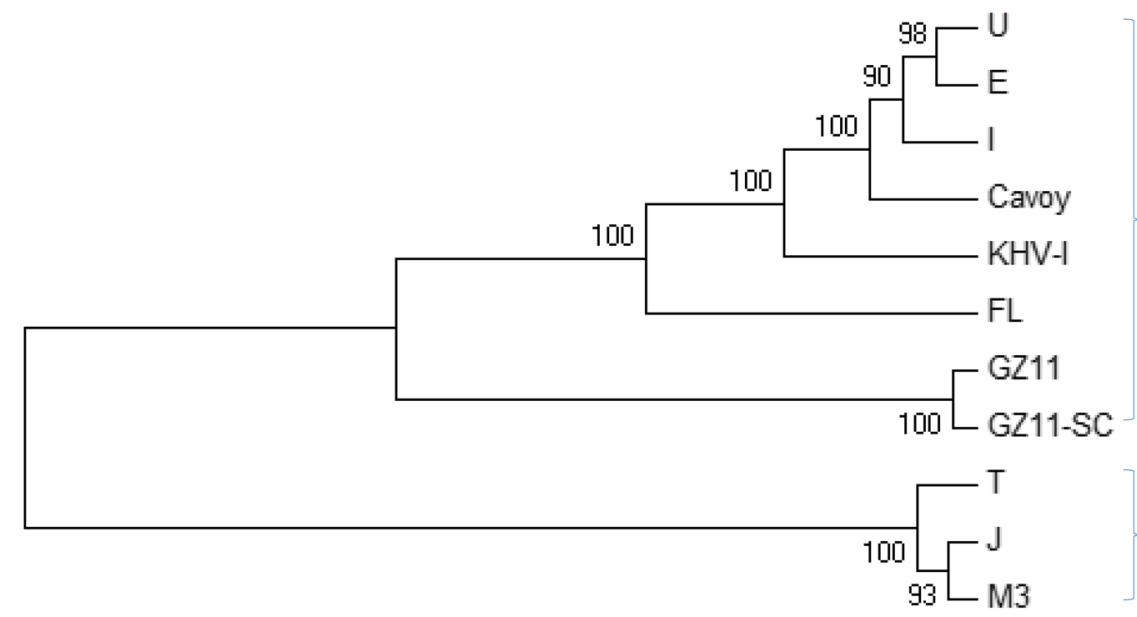

\section{European}

Asian

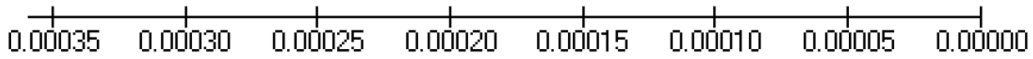

Figure 1 Phylogenetic analysis of CyHV-3 genome sequences. The analysis was based on full-length genome sequences excluding one of the terminal direct repeats. The two previously described lineages are indicated. The phylogenetic tree was built using UPGMA in MEGA6 with 1000 replicates. Values on internal branches refer to the percentage of bootstrap replicates in which the branch was found; only values greater than $50 \%$ are shown. The scale shows the number of substitutions per nucleotide.

Table 2 Recombination events in strain GZ11

\begin{tabular}{|c|c|c|c|c|c|c|c|c|c|c|}
\hline \multirow[t]{2}{*}{ Event } & \multirow[t]{2}{*}{ Genome region $^{a}$} & \multirow[t]{2}{*}{ Major parent ${ }^{\mathbf{b}}$} & \multirow[t]{2}{*}{ Minor parent $^{c}$} & \multicolumn{7}{|c|}{ Detection method $^{d}$} \\
\hline & & & & $\mathbf{R}$ & G & B & $M$ & C & $\mathrm{S}$ & $\mathbf{T}$ \\
\hline 1 & $117-5598$ & $\mathrm{FL}$ & Unknown & $* *$ & * & * & $* *$ & * & ns & * \\
\hline 2 & $77366-94864$ & Cavoy & $\mathrm{T}$ & $* * *$ & $* * *$ & $* * *$ & $* * *$ & $* * *$ & ns & $* * *$ \\
\hline 3 & $269851-271724$ & $E$ & M3 & $* *$ & ns & ns & ns & ns & ns & ns \\
\hline \multicolumn{11}{|c|}{$\begin{array}{l}\text { a Coordinates are listed in relation to the sequence of strain U (GenBank accession number DQ657948.1). The results for strain GZ11-SC were the same as for strain } \\
\text { GZ11. }\end{array}$} \\
\hline \multicolumn{11}{|c|}{$\begin{array}{l}\text { b Major parent strain was automatically predicted by the RDP software. It represents the closest relative of the recombinant strain taking into account the entire } \\
\text { genome but excluding the recombination region. }\end{array}$} \\
\hline \multicolumn{11}{|c|}{$\begin{array}{l}\text { c Minor parent was automatically predicted by the RDP software. It represents the closest relative of the recombinant strain taking into account the recombination } \\
\text { region. }\end{array}$} \\
\hline
\end{tabular}

third, as yet unidentified lineage (Figure 2C). The other two represented the acquisition of 17.5 and $1.9 \mathrm{~kb}$, respectively, from the Asian lineage (Figures $2 \mathrm{~F}$ and $\mathrm{I}$ ). Recombination events 1 and 2 were predicted by 6 detection methods suggesting a high probability of occurrence. In contrast, recombination event 3 was supported by only one detection method and should therefore be treated with caution.

\section{Viral growth in vitro}

Viral fitness in vitro was assessed by viral growth assay and plaque size assay on CCB cells (Figure 3). All seven tested viral strains grew efficiently, reaching titers of at least $10^{5} \mathrm{pfu} / \mathrm{mL}$ at the peak of infection (Figure 3A). The kinetics of viral growth was similar for all strains. The numbers of infectious particles peaked at $4 \mathrm{dpi}$ (strains T, Cavoy, FL and GZ11-SC) or 6 dpi (strains M3, I and $\mathrm{E}$ ), and then declined due to virion inactivation. Despite these general similarities, statistical analyses at $4 \mathrm{dpi}$ revealed quantitative differences between the strains. For example, strain $\mathrm{T}$ (the best-growing strain) reached a titer $>10^{7} \mathrm{pfu} / \mathrm{mL}$, which was $>100$ times that of strain $\mathrm{E}$ (the worst-growing strain). These analyses revealed that strain $\mathrm{T}$ grew more efficiently than all other strains tested $(p<0.001)$, followed by strain Cavoy $(p<0.001$ vs all other strains), strain FL ( $p<0.05$ vs strain GZ11-SC, $p<0.01$ vs 


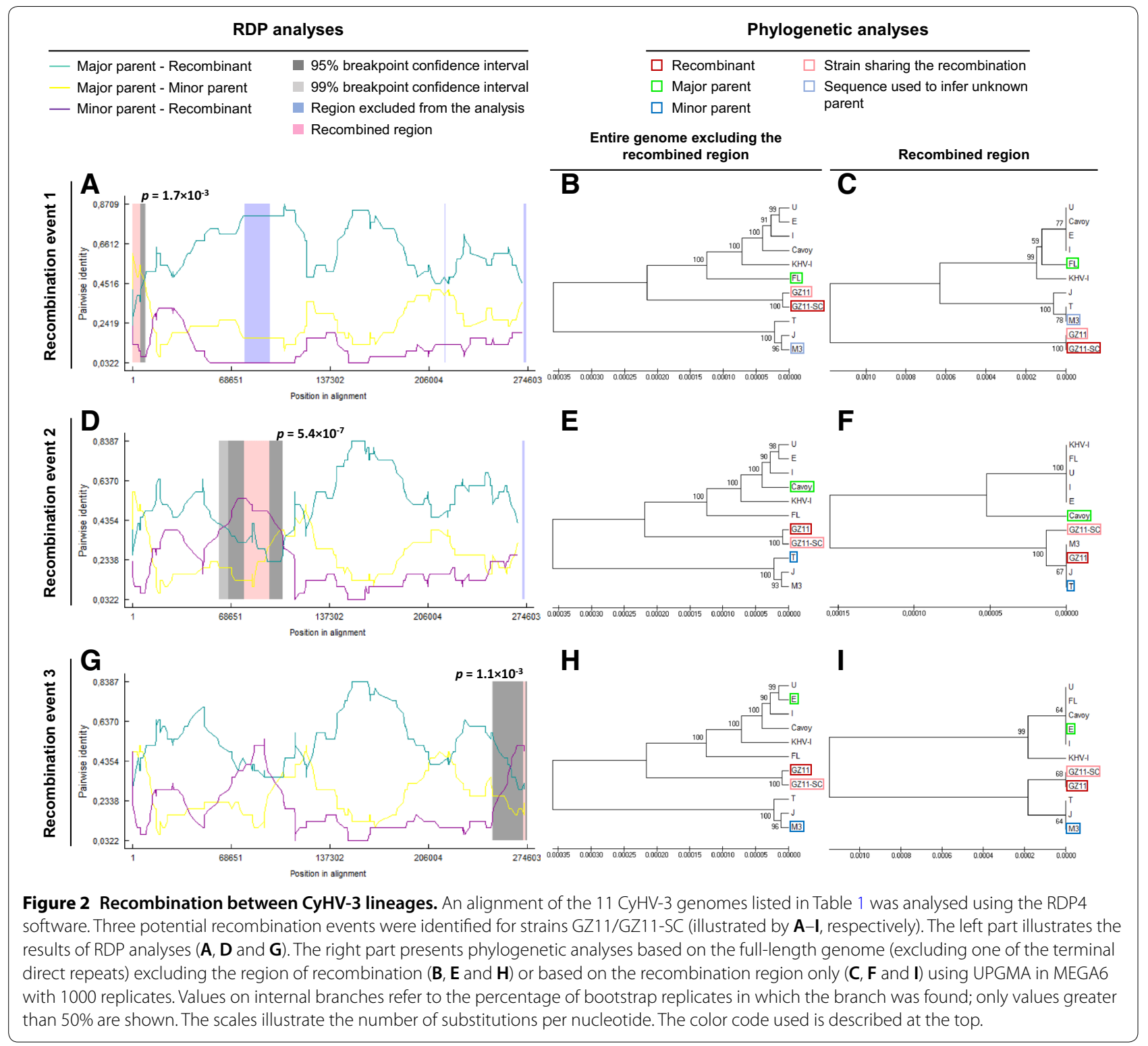

strain M3, and $p<0.001$ vs strains I and E), strains M3, I and GZ11-SC (ns among each other, $p<0.05$ strains I vs $\mathrm{E}$, and $p<0.001$ strains GZ11-SC and M3 vs strain E), and finally strain E. These results demonstrate that CyHV-3 strains exhibited different abilities to grow in vitro that are unrelated to the lineage to which they belong.

All viral strains tested were capable of forming plaques (Figure 3B). However, the results obtained at $10 \mathrm{dpi}$ revealed significant differences in plaque size between strains. The largest plaques were produced by strain $\mathrm{T}$, and these were about twice as big in area as those observed for strain GZ11-SC, which produced the smallest plaques. Statistical analyses of the results obtained at $10 \mathrm{dpi}$ revealed that strain $\mathrm{T}$ produced the largest plaques
( $p<0.001$ vs all strains), followed by strain Cavoy $(p<0.001$ vs all strains), strains FL, M3 and $\mathrm{E}$ (ns between each other, $p<0.01$ vs strain I, $p<0.001$ vs strain GZ11-SC), strain I ( $p<0.01$ vs strain GZ11-SC), and finally strain GZ11-SC. The two parameters used to assess viral replication in vitro (virion production in the extracellular medium and plaque size) were positively correlated $(p<0.05$; Figure 3C).

\section{Virulence in vivo}

The levels of virulence of the seven strains were compared after inoculating fish by immersion in water containing the virus, thereby mimicking a natural infection (Figure 4). 


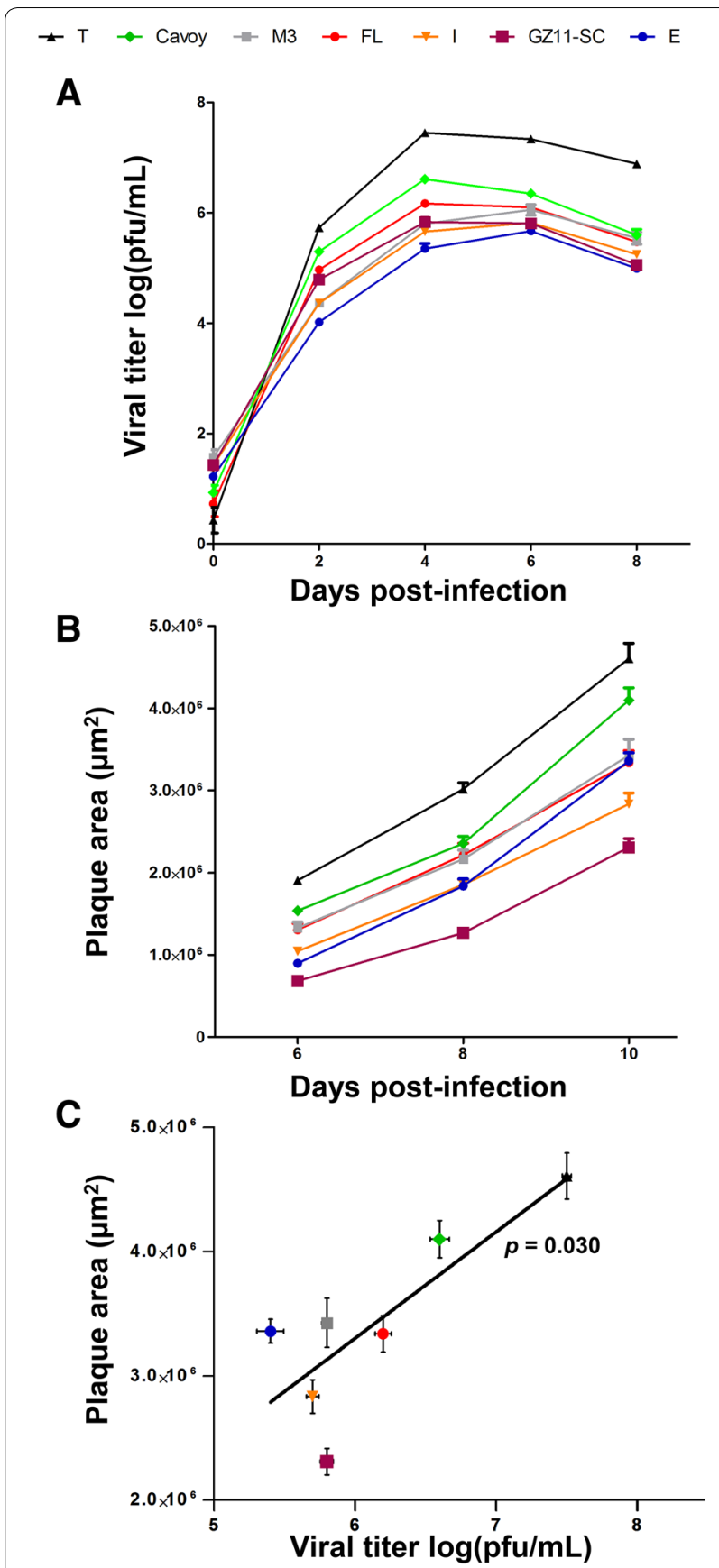

Figure 3 Comparisons of viral growth in vitro. A Viral growth assay. CCB cells were infected with the strains indicated (see top of the figure for the symbol code used) and the log 10 value of the titer $(\mathrm{pfu} / \mathrm{mL})$ in the cell supernatant was determined at the indicated dpi. Data are presented as the mean + SEM (standard error of the mean) of triplicate measurements. B Viral plaque assay. CCB cells were infected with the strains indicated, and plaques areas were measured over time. Data presented are the mean + SEM for measurements of 20 randomly selected plaques. C Correlation between plaque size measured at $10 \mathrm{dpi}$ (B) and viral titers measured at $4 \mathrm{dpi}(\mathbf{A})$. Data presented are the mean \pm SEM.
Regardless of the viral strain used, all infected fish developed CyHV-3 disease. However, the intensity and the kinetics of appearance of clinical signs varied between strains. Strains Cavoy and T induced the mildest disease, with infected fish expressing folding of the dorsal fin, hyperemia and apathy/anorexia. Around 20\% of infected fish succumbed from this infection, including late mortalities induced by neurological symptoms observed in fish surviving the first peak of mortalities. Infection with strain FL led to typical disease including the symptoms described above and associated fin and skin lesions on most fish. Around 70\% of infected fish died from this infection. Infection with strains M3, I, E and GZ11-SC led to very acute and highly virulent disease, with almost all fish dying by $10 \mathrm{dpi}$. None of the mock-infected fish expressed clinical signs or mortality.

Statistical analysis was conducted by two-by-two comparison using a Log-rank test, and the cut-off for significance was adjusted according to the number of comparisons made. Mock-infected groups had higher survival rates compared to all infected fish groups $(p<0.0001)$. Strains Cavoy and T induced higher survival rates than all others strains (ns between these strains, $p<0.0001$ vs all other strains). Strain FL induced a higher survival rate than strains M3, I, E and GZ11-SC $(p<0.0001)$. Strain GZ11-SC was significantly more virulent than strains I and $E(p<0.0001)$, but not more virulent than strain M3. All other comparisons were not significant.

These results indicate that the strains tested can be classified as having low virulence (strains Cavoy and $\mathrm{T}$ ), moderate virulence (strain $\mathrm{FL}$ ) and high virulence (strains M3, E, I and GZ11-SC). As observed for viral growth in vitro, there was no clear association between virulence and genetic lineage. Correlation analysis between viral growth in vitro and virulence in vivo was performed as described above. Positive correlations were found between viral replication in vitro (viral growth assay and viral plaque assay) and survival rate in vivo (Figures 5A and $\mathrm{B}$ ). These results indicate that the adaptation of a viral strain to cell culture is generally associated with its attenuation in vivo.

\section{Disabled genes}

Coupled genomic and biologic comparison of CyHV-3 strains has the potential to indicate biologic roles for genes that are associated with polymorphisms and thus to link them to biological traits. CyHV-3 strains are known to carry mutations (generally frameshifts) in open reading frames (ORFs) that are likely to ablate gene functions, and these mutations may vary from strain to 

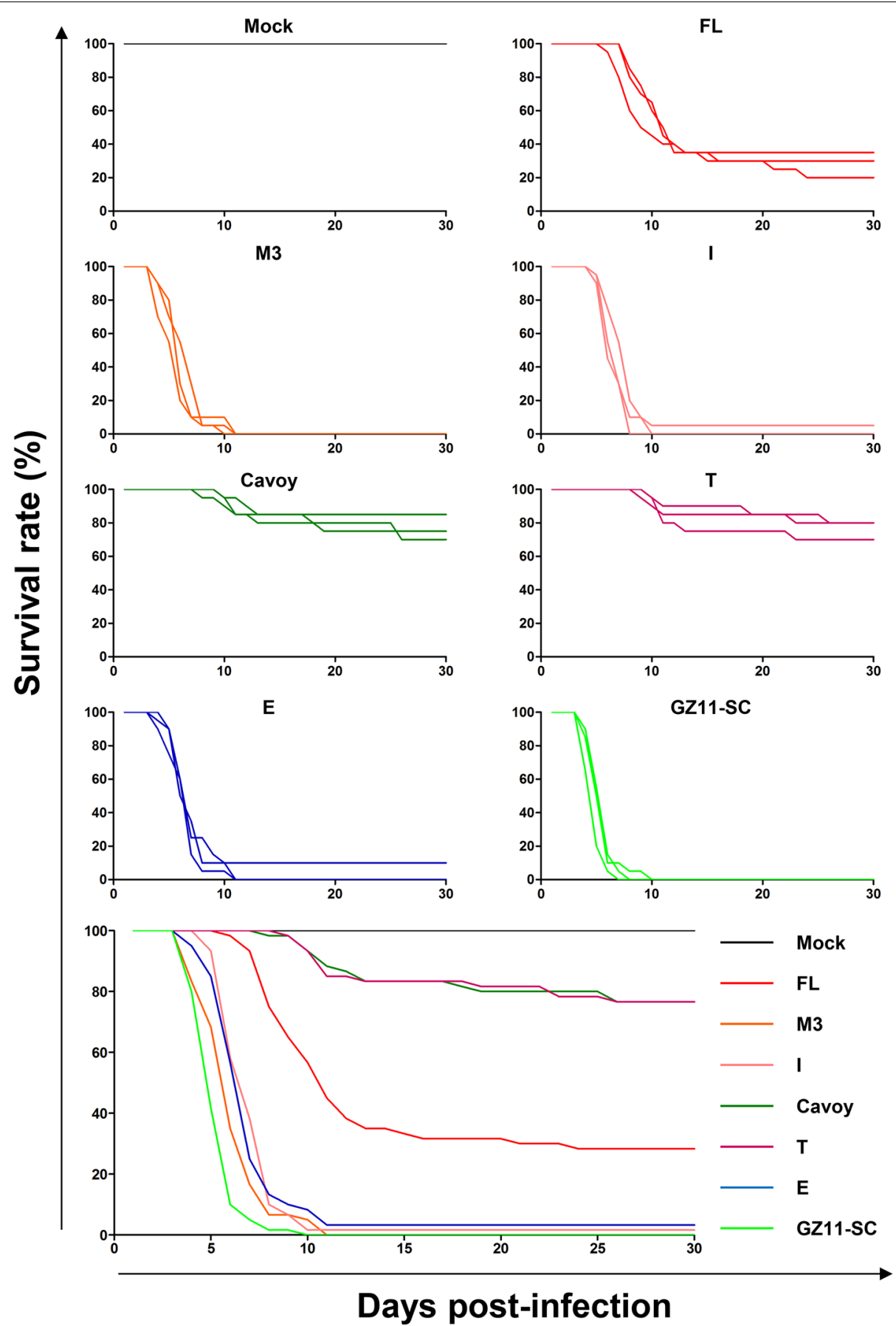

Figure 4 Comparison of virulence in vivo. The virulence of the indicated strains was tested in carp (triplicate groups each consisting of 20 subjects, average weight $5.03 \pm 3.78 \mathrm{~g}, 7$ months old). On day 0 , fish were mock-infected or infected by immersion for $2 \mathrm{~h}$ in water containing $400 \mathrm{pfu} / \mathrm{mL}$ of virus. Survival rate was measured over a period of $30 \mathrm{dpi}$. The smaller upper panels show the survival curves observed for replicates. The larger lower panel shows the mean survival curves based on the three replicates.

strain. The genes disabled in the strains analysed in our study are summarized in Table 3 . Two different situations were noted: ORFs having one or more frameshift near the beginning or in the central part of the ORF that is likely to ablate protein function, and ORFs having a frameshift near the end of the ORF that may not ablate protein function. 


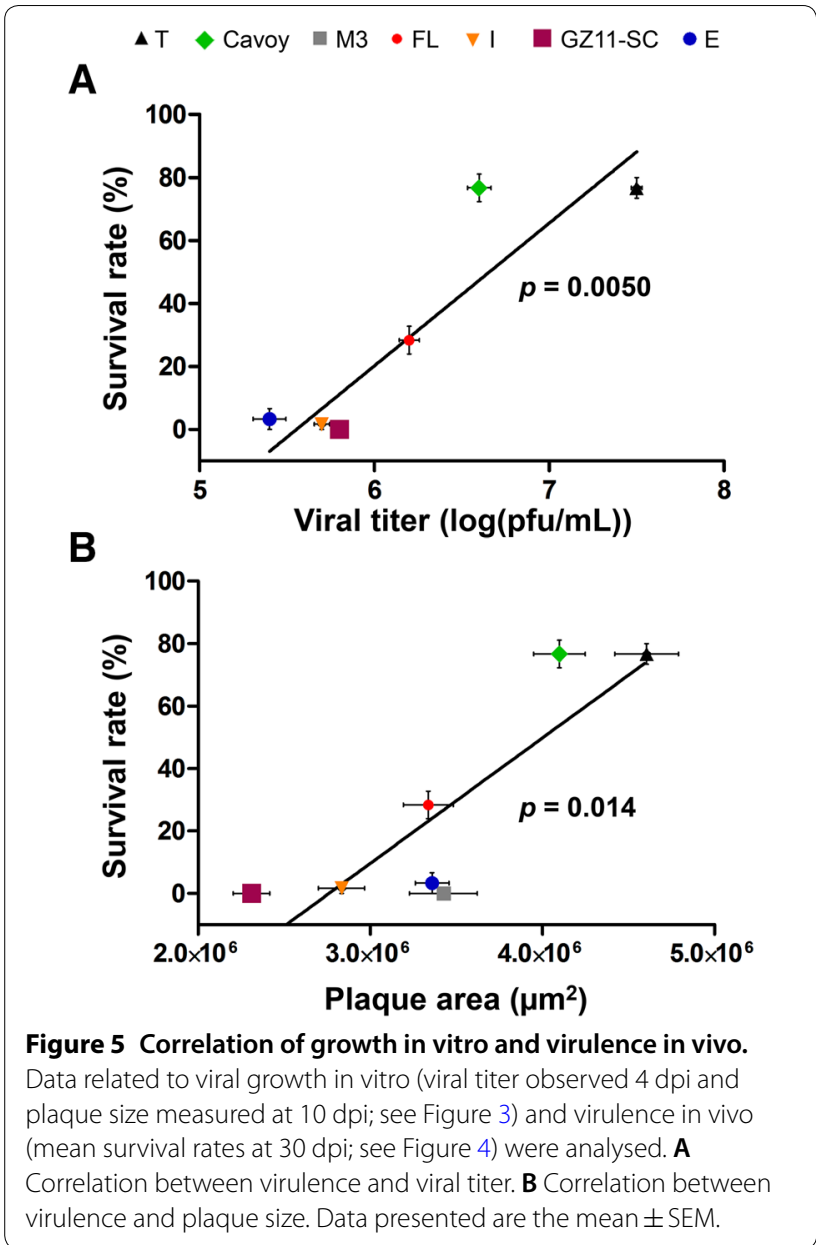

Analysis of these results together with the biologic properties described above led to several conclusions. First, genes that exhibit mutations incompatible with the expression of a functional protein in any strain that is able to grow in cell culture can be classified as nonessential. These include ORF12, ORF26, ORF27, ORF30, ORF40, ORF52, ORF64, ORF105, ORF128 and ORF153. Second, genes that exhibit mutations incompatible with the expression of a functional protein in a highly virulent strain can be classified as non-essential to virulence. These include ORF12, ORF26, ORF30, ORF40, ORF64, ORF105 and ORF128. Third, mutated ORFs that are found exclusively in low or moderate virulence strains can be classified as potentially important virulence genes. These include ORF27, ORF52 and ORF153.

\section{Discussion}

Comparisons of full-length genome sequences and biological properties in vitro and in vivo for seven viral strains allowed us to draw hypotheses about the evolution of CyHV-3 and the roles of some of its genes.
Analysis of full-length CyHV-3 genome sequences revealed a high level of similarity ( $>99 \%$ identity), confirmed the existence of two major genetic lineages while also suggesting the existence of a third, as yet undetected lineage, and highlighted the occurrence of inter-lineage recombination. The level of similarity among $\mathrm{CyHV}-3$ strains is by far greater than that reported for other herpesviruses $[15,16]$ and suggests that the pathogen has emerged relatively recently. This could have been facilitated by the selection for virulence of a viral strain that was already resident in common carp or that had transferred from another host species. However, the existence of identifiable genetic lineages with largely different panoplies of disabled genes, and the single example so far of inter-lineage recombination, suggest that these lineages have been evolving in different host populations. Moreover, the largely consistent association between genetic lineage and geographic origin indicates that the lineages have been spreading independently, with the few inconsistencies and the potential recombination in strain GZ11 (Figure 2 and Table 2) being potentially the consequence of recent geographic spread due to international trading of carp [2]. Importantly, the comparison of the in vitro and in vivo properties of strains belonging to the two lineages did not reveal differences between them, thus implying that inter-lineage polymorphisms do not contribute to the differences in viral fitness observed.

CyHV-3 strains are closely related to each other in sequence, but sufficient differences exist to indicate that their ancestors were infecting various common carp populations long before CyHV-3 disease was first described in the late 1990s. The evolutionary rate of CyHV-3 is unknown, but, if it is similar to that espoused for mammalian alphaherpesviruses $\left(3.5 \times 10^{-8}\right.$ substitutions/ nucleotide/year; [37]), the observation that the European and Asian CyHV-3 lineages differ by up to 6 substitutions in the 5130 bp ORF79 encoding the DNA polymerase catalytic subunit would suggest that the virus has been infecting common carp for some tens of thousands of years. On this basis, CyHV-3 disease is more likely to have emerged in the 1990s as an outcome of shifts in host or environmental co-factors rather than as the result of a virus jumping into common carp from another type of cyprinid fish [38]. The ancestral relationship between common carp and CyHV-3 has also potential implications in the Australian plan to use this virus as a biocontrol measure against invading carp [39]. The apparently long association between CyHV-3 and common carp, and the fact that introductions of common and koi carp into Australia have occurred on many occasions since the 1850s, including more recently than the 1990s [40], imply that the presence of CyHV-3 in Australia cannot be ruled out. CyHV-3-associated mass carp deaths in Australia 


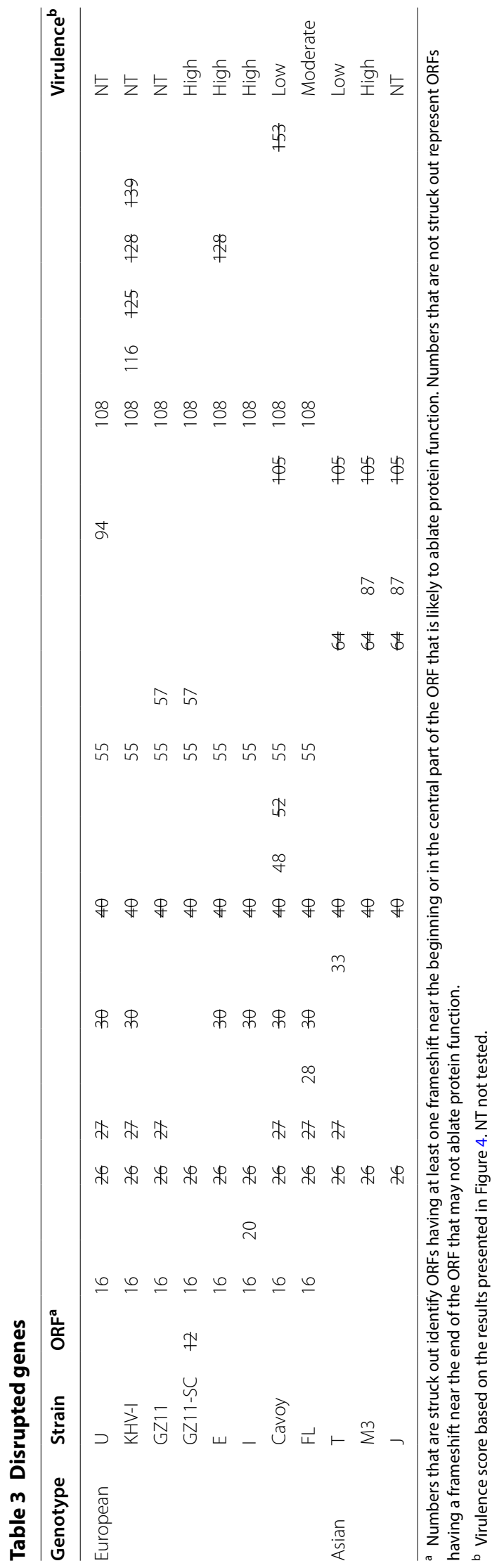


have not been recorded, but this may simply reflect a lack of the environmental co-factors necessary for disease emergence. These considerations have prompted the advice that further assessments of efficacy (not to mention safety) should be carried out before the proposed release is attempted $[39,41]$.

Our results also identified non-essential viral genes and yielded information on their potential roles in virulence. Some genes are evidently not essential for viral growth in vitro and appear to play no essential role in virulence in vivo. However, the laboratory model of infection used would not have revealed genes that function in modification of host behavior, establishment of latency, reactivation from latency, and excretion of virus and transmission to naïve subjects [23, 38, 42]. Further experiments are needed to extend the in vivo studies.

All of the strains tested, including the Cavoy vaccine strain, were to some degree virulent (Figure 4). This observation implicates that none of the strains lacks the function of an essential virulence gene, such as ORF57 [24]. Interestingly, strain Cavoy expressed a level of virulence comparable to that of strain T, killing $20 \%$ of inoculated fish (Figure 4). This residual level of virulence is consistent with earlier observations $[21,43,44]$ and could explain why this vaccine was removed from the market soon after its commercialization in the USA. Given that this strain is still used as a vaccine in some countries, its lack of safety must represent a serious source of concern for the aquaculture industry. Disrupted ORFs that are found exclusively in strains of low or moderate virulence are potentially important virulence genes. They include ORF27 (disrupted in strains FL, T and Cavoy), and ORF52 and ORF153 (both disrupted only in strain Cavoy) (Table 2). Notably, the strains with the highest fitness in cell culture were those associated with the longest cell passage history and the lowest virulence in vivo (Figures $3,4,5)$. Although these results suggest that disrupted genes may be potential virulence factors, they are also consistent with gene loss being fortuitously associated with viral adaptation to cell culture. The latter hypothesis is supported by the observation that viral passage in cell culture is frequently associated with the selection of mutations disabling ORF27 [7]. Further experiments are underway to address this issue.

Our study illustrates the power of coupling genomic and biologic comparisons of viral strains to study viral evolution and pathogenesis. It also provides a firm basis for further research on CyHV-3.

\section{Abbreviations}

CCB: common carp brain; CyHV-3: cyprinid herpesvirus 3; DMEM: Dulbecco's modified essential medium; dpi: days post-infection; FCS: fetal calf serum; indels: insertions or deletions; KHV: koi herpesvirus; ns: not significant; ORF: open reading frame; pfu: plaque-forming unit; RDP: recombination detection program; SEM: standard error of the mean; SNP: single nucleotide polymorphism; UPGMA: unweighted pair-group method with arithmetic means; VNTR: variable number of tandem repeats.

\section{Competing interests}

The authors declare that they have no competing interests.

\section{Authors' contributions}

$M B$ and $A V$ designed the study. YG did most of the experiments and performed statistical analyses. $Y G, M B, A D$ and $A V$ contributed to the writing of the manuscript. YG, MB, and AV drafted the figures. CD, SB and PYL isolated some of the strains. NS, GW and AD determined the genome sequences of the $\mathrm{CyHV}-3$ strains. All authors read and approved the final manuscript.

\section{Acknowledgements}

YG is a research fellow of the Chinese Scholarship Council.

\section{Availability of data and materials}

Genome sequences described in this manuscript are publicly available.

\section{Ethics approval and consent to participate}

The experiments, maintenance and care of fish complied with the guidelines of the European Convention for the Protection of Vertebrate Animals used for Experimental and other Scientific Purposes (CETS no. 123). The animal studies were approved by the local ethics committee of the University of Liège, Belgium (laboratory accreditation no. 1610008, protocol no. 1059). All efforts were made to minimize animal suffering.

\section{Funding}

This work was supported by the University of Liège ("Fonds spéciaux" (FSRF-VT-16/9) and "ARC" (ARC GIGA FARAH 15/19-12) programs), the Belgian Science Policy (BELVIR IAP7/45), the "Fonds National Belge de la Recherche Scientifique" (T.0153.13, J.0094.15 and J.0230.16), and the UK Medical Research Council (MC_UU_12014/3).

\section{Author details}

${ }^{1}$ Immunology-Vaccinology, Department of Infectious and Parasitic Diseases (B43b), Fundamental and Applied Research for Animals \& Health (FARAH), Faculty of Veterinary Medicine, University of Liège, Liège, Belgium. ${ }^{2} \mathrm{MRC}$ University of Glasgow Centre for Virus Research, Glasgow, UK. ${ }^{3}$ MOE Key Laboratory of Aquatic Food Safety/State Key Laboratory for Bio-control, School of Life Sciences, Sun Yat-sen University, Guangzhou, China. ${ }^{4}$ Friedrich-Loeffler Institut, Federal Research Institute for Animal Health, Institute of Infectology, Greifswald-Insel Riems, Germany. ${ }^{5}$ Department of Research and Development, GeneReach, Biotechnology Corporation, Taichung, China.

\section{Publisher's Note}

Springer Nature remains neutral with regard to jurisdictional claims in published maps and institutional affiliations.

Received: 7 February 2018 Accepted: 30 March 2018

Published online: 02 May 2018

\section{References}

1. Boutier M, Ronsmans M, Rakus K, Jazowiecka-Rakus J, Vancsok C, Morvan L, Peñaranda MMD, Stone DM, Way K, van Beurden SJ, Davison AJ, Vanderplasschen A (2015) Chapter three-cyprinid herpesvirus 3: an archetype of fish alloherpesviruses. In: Kielian M, Maramorosch K, Mettenleiter TC (eds) Advances in Virus Research, vol 93. Academic Press, Cambridge, pp 161-256

2. Rodgers CJ, Mohan CV, Peeler EJ (2011) The spread of pathogens through trade in aquatic animals and their products. Rev Sci Tech 30:241-256

3. Ito T, Kurita J, Yuasa K (2014) Differences in the susceptibility of Japanese indigenous and domesticated Eurasian common carp (Cyprinus carpio), identified by mitochondrial DNA typing, to cyprinid herpesvirus 3 (CyHV3). Vet Microbiol 171:31-40 
4. Baumer A, Fabian M, Wilkens MR, Steinhagen D, Runge M (2013) Epidemiology of cyprinid herpesvirus-3 infection in latently infected carp from aquaculture. Dis Aquat Organ 105:101-108

5. Davison AJ, Kurobe T, Gatherer D, Cunningham C, Korf I, Fukuda H, Hedrick RP, Waltzek TB (2013) Comparative genomics of carp herpesviruses. J Virol 87:2908-2922

6. Li W, Lee X, Weng S, He J, Dong C (2015) Whole-genome sequence of a novel Chinese cyprinid herpesvirus 3 isolate reveals the existence of a distinct European genotype in East Asia. Vet Microbiol 175:185-194

7. Aoki T, Hirono I, Kurokawa K, Fukuda H, Nahary R, Eldar A, Davison AJ, Waltzek TB, Bercovier H, Hedrick RP (2007) Genome sequences of three koi herpesvirus isolates representing the expanding distribution of an emerging disease threatening koi and common carp worldwide. JVirol 81:5058-5065

8. Bigarre L, Baud M, Cabon J, Antychowicz J, Bergmann SM, Engelsma M, Pozet F, Reichert M, Castric J (2009) Differentiation between Cyprinid herpesvirus type-3 lineages using duplex PCR. J Virol Methods 158:51-57

9. Kurita J, Yuasa K, Ito T, Sano M, Hedrick RP, Engelsma MY, Haenen OLM, Sunarto A, Kholidin EB, Chou HY, Tung MC, de la Pena L, Lio-Po G, Tu C, Way K, lida T (2009) Molecular epidemiology of koi herpesvirus. Fish Pathol 44:59-66

10. Dong C, Li X, Weng S, Xie S, He J (2013) Emergence of fatal European genotype CyHV-3/KHV in mainland China. Vet Microbiol 162:239-244

11. Sunarto A, McColl KA, Crane MS, Sumiati T, Hyatt AD, Barnes AC, Walker PJ (2011) Isolation and characterization of koi herpesvirus (KHV) from Indonesia: identification of a new genetic lineage. J Fish Dis 34:87-101

12. Deback C, Boutolleau D, Depienne C, Luyt CE, Bonnafous P, GautheretDejean A, Garrigue I, Agut H (2009) Utilization of microsatellite polymorphism for differentiating herpes simplex virus type 1 strains. J Clin Microbiol 47:533-540

13. Avarre JC, Madeira JP, Santika A, Zainun Z, Baud M, Cabon J, Caruso D, Castric J, Bigarre L, Engelsma M, Maskur M (2011) Investigation of Cyprinid herpesvirus-3 genetic diversity by a multi-locus variable number of tandem repeats analysis. J Virol Methods 173:320-327

14. Avarre JC, Santika A, Bentenni A, Zainun Z, Madeira JP, Maskur M, Bigarre L, Caruso D (2012) Spatio-temporal analysis of cyprinid herpesvirus 3 genetic diversity at a local scale. J Fish Dis 35:767-774

15. Szpara ML, Gatherer D, Ochoa A, Greenbaum B, Dolan A, Bowden RJ, Enquist LW, Legendre M, Davison AJ (2014) Evolution and diversity in human herpes simplex virus genomes. J Virol 88:1209-1227

16. Renner DW, Szpara ML (2017) Impacts of genome-wide analyses on our understanding of human herpesvirus diversity and evolution. J Virol 92:e00908-17

17. Hammoumi S, Vallaeys T, Santika A, Leleux P, Borzym E, Klopp C, Avarre $J C$ (2016) Targeted genomic enrichment and sequencing of CyHV-3 from carp tissues confirms low nucleotide diversity and mixed genotype infections. PeerJ 4:e2516

18. Neukirch M, Böttcher K, Sumrarn B (1999) Isolation of a virus from koi with altered gills. Bull Eur Assoc Fish Pathol 19:221-224

19. Ronen A, Perelberg A, Abramowitz J, Hutoran M, Tinman S, Bejerano I, Steinitz M, Kotler M (2003) Efficient vaccine against the virus causing a lethal disease in cultured Cyprinus carpio. Vaccine 21:4677-4684

20. Perelberg A, Ronen A, Hutoran M, Smith Y, Kotler M (2005) Protection of cultured Cyprinus carpio against a lethal viral disease by an attenuated virus vaccine. Vaccine 23:3396-3403

21. Weber EP 3rd, Malm KV, Yun SC, Campbell LA, Kass PH, Marty GD, Salonius K, Dishon A (2014) Efficacy and safety of a modified-live cyprinid herpesvirus 3 vaccine in koi (Cyprinus carpio koi) for prevention of koi herpesvirus disease. Am J Vet Res 75:899-904

22. Mletzko A, Amtmann A, Bergmann S, Lee P, Christian J, Buchholz R, Becker A (2017) Inoculation of cyprinid herpesvirus 3 (CyHV-3) on common carp brain cells-influence of process parameters on virus yield. In Vitro Cell Dev Biol Anim 53:579-585

23. Boutier M, Ronsmans M, Ouyang P, Fournier G, Reschner A, Rakus K, Wilkie GS, Farnir F, Bayrou C, Lieffrig F (2015) Rational development of an attenuated recombinant cyprinid herpesvirus 3 vaccine using prokaryotic mutagenesis and in vivo bioluminescent imaging. PLoS Pathog 11:e1004690

24. Boutier M, Gao Y, Vancsok C, Suarez NM, Davison AJ, Vanderplasschen A (2017) Identification of an essential virulence gene of cyprinid herpesvirus 3. Antiviral Res 145:60-69
25. Katoh K, Rozewicki J, Yamada KD (2018) MAFFT online service: multiple sequence alignment, interactive sequence choice and visualization. Brief Bioinform (in press)

26. Tamura K, Stecher G, Peterson D, Filipski A, Kumar S (2013) MEGA6: molecular evolutionary genetics analysis version 6.0. Mol Biol Evol 30:2725-2729

27. Martin DP, Murrell B, Khoosal A, Muhire B (2017) Detecting and analyzing genetic recombination using RDP4. Methods Mol Biol 1525:433-460

28. Martin D, Rybicki E (2000) RDP: detection of recombination amongst aligned sequences. Bioinformatics 16:562-563

29. Mansai SP, Innan H (2010) The power of the methods for detecting interlocus gene conversion. Genetics 184:517-527

30. Martin DP, Posada D, Crandall KA, Williamson C (2005) A modified bootscan algorithm for automated identification of recombinant sequences and recombination breakpoints. AIDS Res Hum Retrovir 21:98-102

31. Bay RA, Bielawski JP (2011) Recombination detection under evolutionary scenarios relevant to functional divergence. J Mol Evol 73:273-286

32. Posada D, Crandall KA (2001) Evaluation of methods for detecting recombination from DNA sequences: computer simulations. Proc Natl Acad Sci U S A 98:13757-13762

33. Gibbs MJ, Armstrong JS, Gibbs AJ (2000) Sister-scanning: a Monte Carlo procedure for assessing signals in recombinant sequences. Bioinformatics 16:573-582

34. Lam HM, Ratmann O, Boni MF (2018) Improved algorithmic complexity for the 3SEQ recombination detection algorithm. Mol Biol Evol 35:247-251

35. Costes B, Raj VS, Michel B, Fournier G, Thirion M, Gillet L, Mast J, Lieffrig F, Bremont M, Vanderplasschen A (2009) The major portal of entry of koi herpesvirus in Cyprinus carpio is the skin. J Virol 83:2819-2830

36. Abràmoff MD, Magalhães PJ, Ram SJ (2004) Image processing with ImageJ. Biophotonics Intern 11:36-42

37. McGeoch DJ, Cook S, Dolan A, Jamieson FE, Telford EA (1995) Molecular phylogeny and evolutionary timescale for the family of mammalian herpesviruses. J Mol Biol 247:443-458

38. Rakus K, Ronsmans M, Forlenza M, Boutier M, Piazzon MC, JazowieckaRakus J, Gatherer D, Athanasiadis A, Farnir F, Davison AJ, Boudinot P, Michiels T, Wiegertjes GF, Vanderplasschen A (2017) Conserved fever pathways across vertebrates: a herpesvirus expressed decoy TNF-alpha receptor delays behavioral fever in fish. Cell Host Microbe 21:244-253

39. Marshall J, Davison AJ, Kopf RK, Boutier M, Stevenson P, Vanderplasschen A (2018) Biocontrol of invasive carp: risks abound. Science 359:877

40. Haynes GD, Gilligan DM, Grewe P, Moran C, Nicholas FW (2010) Population genetics of invasive common carp Cyprinus carpio L. in coastal drainages in eastern Australia. J Fish Biol 77:1150-1157

41. Lighten J, van Oosterhout C (2017) Biocontrol of common carp in Australia poses risks to biosecurity. Nat Ecol Evol 1:87

42. Reed AN, Izume S, Dolan BP, LaPatra S, Kent M, Dong J, Jin L (2014) Identification of B cells as a major site for cyprinid herpesvirus 3 latency. J Virol 88:9297-9309

43. Perelberg A, llouze M, Kotler M, Steinitz M (2008) Antibody response and resistance of Cyprinus carpio immunized with cyprinid herpes virus 3 (CyHV-3). Vaccine 26:3750-3756

44. Zak T, Perelberg A, Magen I, Milstein A, Joseph D (2007) Heterosis in the growth rate of Hungarian-Israeli common carp crossbreeds and evaluation of their sensitivity to koi herpes virus (KHV) disease. Isr J Aquacult Bamidgeh 59:63-72

45. Costes B, Fournier G, Michel B, Delforge C, Raj VS, Dewals B, Gillet L, Drion P, Body A, Schynts F, Lieffrig F, Vanderplasschen A (2008) Cloning of the koi herpesvirus genome as an infectious bacterial artificial chromosome demonstrates that disruption of the thymidine kinase locus induces partial attenuation in Cyprinus carpio koi. J Virol 82:4955-4964

46. Vancsok C, Penaranda MMD, Raj VS, Leroy B, Jazowiecka-Rakus J, Boutier M, Gao Y, Wilkie GS, Suarez NM, Wattiez R, Gillet L, Davison AJ, Vanderplasschen AFC (2017) Proteomic and functional analyses of the virion transmembrane proteome of Cyprinid herpesvirus 3. J Virol 91:e01209-17

47. Klafack S, Wang Q, Zeng W, Wang Y, Li Y, Zheng S, Kempter J, Lee PY, Matras M, Bergmann SM (2017) Genetic variability of koi herpesvirus in vitro-a natural event? Front Microbiol 8:982 